\title{
Construction of a high-coverage bacterial artificial chromosome library and comprehensive genetic linkage map of yellowtail Seriola quinqueradiata
}

\author{
Kanako Fuji ${ }^{1 \dagger}$, Takashi Koyama ${ }^{1 \dagger}$, Wataru Kai ${ }^{2}$, Satoshi Kubota ${ }^{1}$, Kazunori Yoshida ${ }^{3}$, Akiyuki Ozaki ${ }^{2}$, Jun-ya Aoki ${ }^{2}$,
} Yumi Kawabata ${ }^{2}$, Kazuo Araki ${ }^{2}$, Tatsuo Tsuzaki ${ }^{3}$, Nobuaki Okamoto ${ }^{1}$ and Takashi Sakamoto ${ }^{{ }^{*}}$

\begin{abstract}
Background: Japanese amberjack/yellowtail (Seriola quinqueradiata) is a commonly cultured marine fish in Japan. For cost effective fish production, a breeding program that increases commercially important traits is one of the major solutions. In selective breeding, information of genetic markers is useful and sufficient to identify individuals carrying advantageous traits but if the aim is to determine the genetic basis of the trait, large insert genomic DNA libraries are essential. In this study, toward prospective understanding of genetic basis of several economically important traits, we constructed a high-coverage bacterial artificial chromosome (BAC) library, obtained sequences from the BAC-end, and constructed comprehensive female and male linkage maps of yellowtail using Simple Sequence Repeat (SSR) markers developed from the BAC-end sequences and a yellowtail genomic library.
\end{abstract}

Results: The total insert length of the BAC library we constructed here was estimated to be approximately 11 $\mathrm{Gb}$ and hence 16-times larger than the yellowtail genome. Sequencing of the BAC-ends showed a low fraction of repetitive sequences comparable to that in Tetraodon and fugu. A total of 837 SSR markers developed here were distributed among 24 linkage groups spanning 1,026.70 and 1,057.83 cM with an average interval of 4.96 and $4.32 \mathrm{cM}$ in female and male map respectively without any segregation distortion. Oxford grids suggested conserved synteny between yellowtail and stickleback.

Conclusions: In addition to characteristics of yellowtail genome such as low repetitive sequences and conserved synteny with stickleback, our genomic and genetic resources constructed and revealed here will be powerful tools for the yellowtail breeding program and also for studies regarding the genetic basis of traits.

Keywords: Yellowtail, BAC library, Linkage map

\section{Background}

Species of yellowtail (family Carangidae) are widely distributed in the world's ocean and are major target species for fisheries and aquaculture. The Japanese amberjack/yellowtail (Seriola quinqueradiata) is one of the most popular fish for consumption in Japan, where about 150,000 tons of farmed fish are produced each year. Although there is a huge market demand, seeds of this fish mostly rely on wild catch and hence artificial seed production is required for stable cultivation and breeding as well as reducing the negative effects of

\footnotetext{
* Correspondence: takashis@kaiyodai.ac.jp

${ }^{\dagger}$ Equal contributors

${ }^{1}$ Faculty of Marine Science, Tokyo University of Marine Science and

Technology, 4-5-7, Konan, Minato-ku, Tokyo 108-8477, Japan

Full list of author information is available at the end of the article
}

large-scale sampling of seed fish on natural stock. It is well known that using cultured brood fish for seed production reduces the environmental impact and allows the selection of commercially important traits and in such a case, marker-assisted selection (MAS) breeding based on studies regarding quantitative trait locus (QTL) is powerful and cost effective choice. Indeed, QTL studies have been performed in several fishes so far to improve production and lifehistory traits such as disease resistance and enhance growth rate [1]. To enable the QTL studies, linkage maps are required. In yellowtail, although a female linkage map has been constructed with 180 microsatellite markers [2,3], the number of markers is not sufficient for fine QTL mapping

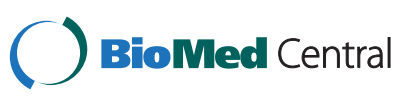

(C) 2014 Fuji et al.; licensee BioMed Central Ltd. This is an Open Access article distributed under the terms of the Creative Commons Attribution License (http://creativecommons.org/licenses/by/2.0), which permits unrestricted use, distribution, and reproduction in any medium, provided the original work is properly credited. The Creative Commons Public Domain Dedication waiver (http://creativecommons.org/publicdomain/zero/1.0/) applies to the data made available in this article, unless otherwise stated. 
and/or MAS in yellowtail breeding programs. Therefore, a higher-density linkage map is still required.

To isolate simple sequence repeats (SSRs) such as microsatellites and to further investigate the genetic basis of the traits, genomic information is essential. The sequences were isolated from genomic library and of the genomic library, one using bacterial artificial chromosome (BAC) system, called the BAC library, has been frequently used such as to generate whole-genome physical maps by DNA fingerprinting [4], to develop sequencetagged connectors [5], and to sequence the genome itself [6] because of their insert size capacity, reproducibility and stability as the DNA sample [7]. By integrating BAC clones into linkage maps using BAC-derived sequences such as BAC-end sequences (BESs), BAC library also play important roles in genetic studies and subsequent positional cloning [8]. BAC libraries have been developed in several domestic animals, e.g. cattle [9], pig [10] and sheep [11], and in fishes, salmon [12], catfish [13], rainbow trout, carp, tilapia [14,15], European sea bass [16,17] and barramundi [18] but in yellowtails a BAC library has not yet been constructed.

In this study, to advance yellowtail genomic and genetic resources and for understanding of the genetic basis of several traits, we constructed a high-coverage BAC library, obtained BESs for preliminary survey of the genomic content and constructed comprehensive genetic linkage map of yellowtail.

\section{Results and discussion}

\section{BAC library construction and BAC end sequencing}

The yellowtail genomic DNA content, represented as $\mathrm{C}$-value, was estimated to be $0.7 \mathrm{pg} / \mathrm{cell}$ (data not shown) using flow cytometric analysis and hence the genome size was calculated to be approximately $685 \mathrm{Mb}$. Of 100 randomly selected BAC clones, 71 (71\%) contained inserts, indicating that approximately 78,520 (71\% of 110,592 clones) clones had an insert. The size distribution of the 71 clones with inserts was from about $20 \mathrm{~kb}$ to $220 \mathrm{~kb}$ and average insert length was $140.7 \mathrm{~kb}$ (data not shown). Therefore, it is estimated that the total length of the yellowtail BAC library insert DNA was approximately $11 \mathrm{~Gb}$ and was 16-times larger than the yellowtail genome. It is known that a minimum of $5-10 \times$ coverage across the entire genome is required for a BAC library to be useful for positional cloning, physical mapping, and genome sequencing [19]. Therefore, the yellowtail BAC library is sufficient for further genomic/ genetic analysis except for studies regarding W-linked genes because of our ZZ male derived DNA source [20].

By sequencing both ends of randomly-selected 2,960 BAC clones, a total of 5,920 raw reads were obtained, and of those reads, 4,956 reads $(2,471$ in the SP6 side and 2,485 in the T7 side) were qualified for subsequent repeat identification and BLAST search (GA867436 GA872391). Total length of the qualified BESs was $3,074,133$ bp with an average size of $620 \mathrm{bp}$, representing approximately $0.45 \%$ of the yellowtail genome. The GC content was estimated to be $41.36 \%$, which is almost the same as other fishes (Takifugu rubripes: 45.46\%; Gasterosteus aculeatus: 44.60\%; Oryzias latipes: 40.46\%; Tetraodon nigroviridis: 46.43\%) (http://esper.lab.nig.ac.jp/ genome-composition-database/).

\section{Preliminary survey of genomic content using BESs Repeat content}

The repeat elements were searched and screened from the qualified BESs. Total 211,184 bp (6.87\%) of the qualified BESs are assigned to the repeat elements, of which $60,380 \mathrm{bp}$ (1.96\%), 40,242 bp (1.31\%), 21,563 bp $(0.70 \%)$ and 76,925 bp $(2.50 \%)$ were classified as retroelements, DNA transposons, small RNA and simple repeats, respectively (Table 1). Assuming that the BAC library represents the genome of target specie, the

\section{Table 1 Repeat content of the yellowtail BESs}

\begin{tabular}{|c|c|c|c|}
\hline & $\begin{array}{l}\text { Number of } \\
\text { elements }\end{array}$ & $\begin{array}{c}\text { Length } \\
\text { occupied (bp) }\end{array}$ & $\%$ of sequence \\
\hline Retroelements & 284 & 60380 & 1.96 \\
\hline SINES: & 57 & 6098 & 0.20 \\
\hline Penelope & 6 & 1229 & 0.04 \\
\hline LINEs: & 124 & 28193 & 0.92 \\
\hline L2/CR1/Rex & 81 & 16689 & 0.54 \\
\hline R1/LOA/Jockey & 2 & 112 & 0.00 \\
\hline $\mathrm{R} 2 / \mathrm{R} 4 / \mathrm{NeSL}$ & 7 & 1703 & 0.06 \\
\hline RTE/Bov-B & 24 & 6124 & 0.20 \\
\hline L1/01 N4 & 6 & 2453 & 0.08 \\
\hline LTR elements: & 103 & 26089 & 0.85 \\
\hline BEL/Pao & 19 & 9346 & 0.30 \\
\hline Ty1/Copia & 1 & 629 & 0.02 \\
\hline Gypsy/DIRS1 & 65 & 14242 & 0.46 \\
\hline Retroviral & 4 & 881 & 0.03 \\
\hline DNA transposons & 281 & 40242 & 1.31 \\
\hline hobo-Activator & 73 & 5609 & 0.18 \\
\hline Tc1-IS630-Pogo & 96 & 20720 & 0.67 \\
\hline PiggyBac & 13 & 1887 & 0.06 \\
\hline Tourist/Harbinger & 11 & 1349 & 0.04 \\
\hline Unclassified: & 15 & 1165 & 0.04 \\
\hline $\begin{array}{l}\text { Total interspersed } \\
\text { repeats: }\end{array}$ & & 101787 & 3.31 \\
\hline Small RNA: & 69 & 21563 & 0.70 \\
\hline Satellites: & 12 & 1797 & 0.06 \\
\hline Simple repeats: & 1842 & 76925 & 2.50 \\
\hline Low complexity: & 237 & 11293 & 0.37 \\
\hline
\end{tabular}


abundance of the repetitive sequence in yellowtail genome is lower than the majority of teleost fishes studied so far such as rainbow trout (59.5\%) [21], common carp (17.3\%) [15], channel catfish (11.9\%) [22] and Nile tilapia (14.0\%) [23] and comparable to that in Tetraodon (6.2\%) and in fugu (4.3\%) [24].

A total of 1,845 simple sequence repeats (SSRs) were identified from the BESs (Table 1). Of the SSRs, dinucleotide repeats, particularly AC/GT repeats including $\mathrm{CA} / \mathrm{TG}$ repeats, were the most abundant (Table 2).

\section{Homology to other teleost genomes}

To identify the homology between yellowtail and other fishes, the yellowtail qualified BESs were subjected to BLASTx and BLASTn searches against eight teleost proteomes and genomes respectively. The highest number of top hits, highest average bit score and \% identity were observed in yellowtail-Nile tilapia in both BLAST results (Table 3). Total length of the queries in BLASTx hits between yellowtail and Nile tilapia was estimated to be $198,090 \mathrm{bp}$ indicating that $6.4 \%$ of the qualifed BESs was protein coding sequence. The high sequence similarity between yellowtail and Nile tilapia can be explained by their phylogenic positions where they are both assigned

Table 2 SSR distribution in the yellowtail BESs

\begin{tabular}{|c|c|c|}
\hline Repeat & Type & Number \\
\hline \multirow[t]{2}{*}{ Monomer } & $A / T$ & 234 \\
\hline & $\mathrm{G} / \mathrm{G}$ & 12 \\
\hline \multirow[t]{3}{*}{ Dimer } & $\mathrm{AC} / \mathrm{GT}$ & 589 \\
\hline & $\mathrm{AG} / \mathrm{CT}$ & 116 \\
\hline & AT/AT & 75 \\
\hline \multirow[t]{7}{*}{ Trimer } & AAT/ATT & 64 \\
\hline & AGC/GCT & 29 \\
\hline & $\mathrm{AAC/GTT}$ & 20 \\
\hline & ATC/GAT & 20 \\
\hline & $\mathrm{CTC} / \mathrm{GAG}$ & 20 \\
\hline & $\mathrm{AGG} / \mathrm{CCT}$ & 16 \\
\hline & Others & 41 \\
\hline \multirow[t]{5}{*}{ Tetramer } & AAAT/ATTा & 48 \\
\hline & AAAC/GTT & 28 \\
\hline & AGAT/ATCT & 25 \\
\hline & ACAG/CTGT & 16 \\
\hline & Others & 145 \\
\hline Pentamer & & 132 \\
\hline Hexamer & & 141 \\
\hline Heptamer & & 63 \\
\hline Octomer & & 5 \\
\hline Nanomer & & 5 \\
\hline Decamer & & 1 \\
\hline
\end{tabular}

in the order Perciformes [25]. In the BLASTn result, the second-highest number of top hit was observed in the yellowtail-stickleback comparison (Table 3). The high sequence similarity between stickleback and species in Perciformes such as striped bass and gilthead seabream has been reported and therefore our data is consistent with the previous observations [26,27].

\section{Genetic linkage map}

Out of the 743 primer pairs designed from the qualified BESs, 373 primer pairs $(27$ mononucleotide repeats, 285 dinucleotide repeats, 31 trinucleotide repeats, 26 tetranucleotide repeats, 3 pentanucleotide repeats and 1 hexanucleotide repeat) produced amplicons. In addition to the 464 microsatellite markers derived from the genomic library Ohara et al. developed [2,3], 837 markers in total were included in the yellowtail genetic linkage maps (Additional file 1). No segregation distortion was observed in any markers and hence lethal allele-linked markers were not included in our marker set.

Resultant yellowtail female and male genetic map consists of 715 and 702 markers including 232 and 271 framework markers, spanning 1,026.65 and 1,057.83 cM Kosambi with an average interval 4.96 and $4.32 \mathrm{cM}$ on 24 linkage groups respectively (Table 4, Figure 1). The number of chromosomes in yellowtail has been reported to be $2 n=48$ and hence the SSR markers we developed are distributed throughout the yellowtail genome [28]. The "gaps" observed in Squ21 and 24 in male and both map respectively might be caused by "recombination hot-spots" where recombination occurs frequently (Figure 1). The genome length was estimated to be 1,274.64 $\left(L_{1}\right)$ and 1,284.34 $\left(L_{2}\right) \mathrm{cM}$ in the female and 1,282.35 $\left(L_{1}\right)$ and $1,285.45\left(L_{2}\right) \mathrm{cM}$ in the male map by the two different methods respectively (see Materials and Methods). Using formula $c=1-e^{-2 d n / L}$ and estimated genome length $L$, coverage of the female and male map is estimated to be 83.3 to $83.9 \%$ respectively (Table 4 ). Considering the average interval less than $10 \mathrm{cM}$ and the genome coverage, we concluded that the yellowtail genetic map was sufficient for further QTL studies [29].

Identification orthologous chromosomes with other fishes In addition to the BAC or whole genome sequence, comparative genome analysis especially conserved synteny would be helpful for fine-scale QTL analyses and/ or understanding the genetic basis of the traits [30,31]. BLAST searches of the 818 mapped yellowtail loci against medaka, Tetraodon, stickleback, fugu and zebrafish proved that 25.7, 23.0, 42.2, 24.4 and 9.4\% of the loci were mapped to each genome sequence. Oxford grids showed that eighteen linkage group pairs between yellowtail and stickleback retained a one-to-one relationship, and another three stickleback and six yellowtail 
Table 3 Summary of BLAST searches of the yellowtail qualified BESs against eight fish genomes and proteomes

\begin{tabular}{|c|c|c|c|c|c|c|c|c|}
\hline \multirow[b]{2}{*}{ Species } & \multicolumn{4}{|c|}{ BLASTx } & \multicolumn{4}{|c|}{ BLASTn } \\
\hline & No. of top hits & E-value* & Bit score* & $\%$ identity* & No. of top hits & E-value* & Bit score* & $\%$ identity* \\
\hline Atlantic cod & 630 & $2.2 \mathrm{E}-11$ & 99.1 & 75.6 & 720 & 2.7E-11 & 125.5 & 88.8 \\
\hline Medaka & 672 & 1.7E-11 & 102.7 & 77.2 & 1,122 & $1.6 \mathrm{E}-11$ & 145.6 & 88.9 \\
\hline Nile tilapia & 768 & $1.8 \mathrm{E}-11$ & 1085 & 80.8 & 2,162 & $1.2 \mathrm{E}-11$ & 172.7 & 90.0 \\
\hline Platyfish & 714 & $1.9 \mathrm{E}-11$ & 105.4 & 77.8 & 1,339 & $1.5 \mathrm{E}-11$ & 147.5 & 89.2 \\
\hline Tetraodon & 670 & $1.6 \mathrm{E}-11$ & 104.2 & 77.6 & 891 & $1.5 \mathrm{E}-11$ & 144.9 & 89.0 \\
\hline Stickleback & 704 & $2.0 \mathrm{E}-11$ & 107.1 & 80.4 & 1,718 & $1.8 \mathrm{E}-11$ & 160.4 & 89.8 \\
\hline Fugu & 695 & 2.1E-11 & 106.8 & 78.6 & 1,136 & $3.4 \mathrm{E}-11$ & 131.3 & 89.6 \\
\hline Zebrafish & 640 & $2.8 \mathrm{E}-11$ & 98.8 & 72.5 & 361 & 4.2E-11 & 114.4 & 87.7 \\
\hline
\end{tabular}

*Average value of the tophits.

Table 4 Summary of the yellowtail genetic map

\begin{tabular}{|c|c|c|c|c|c|c|c|c|c|c|}
\hline & \multicolumn{5}{|c|}{ Female map } & \multicolumn{5}{|c|}{ Male map } \\
\hline & \multicolumn{3}{|c|}{ No. of markers } & \multicolumn{2}{|c|}{ Genome length } & \multicolumn{3}{|c|}{ No. of markers } & \multicolumn{2}{|c|}{ Genome length } \\
\hline & All & Framework & Length (cM) & $L_{1}(\mathrm{cM})$ & $\overline{L_{2}(\mathrm{cM})}$ & All & Framework & Length (cM) & $L_{1}(\mathrm{cM})$ & $\overline{L_{2}(\mathrm{cM})}$ \\
\hline Squ1 & 33 & 11 & 48.19 & 58.11 & 57.83 & 34 & 15 & 49.28 & 57.91 & 56.32 \\
\hline Squ2 & 49 & 14 & 49.27 & 59.19 & 56.85 & 48 & 18 & 43.45 & 52.09 & 48.56 \\
\hline Squ3 & 29 & 10 & 40.17 & 50.09 & 49.10 & 29 & 18 & 54.97 & 63.60 & 61.43 \\
\hline Squ4 & 28 & 9 & 42.82 & 52.74 & 53.52 & 25 & 3 & 5.57 & 14.20 & 11.14 \\
\hline Squ5 & 38 & 9 & 59.51 & 69.43 & 74.39 & 39 & 17 & 50.24 & 58.87 & 56.52 \\
\hline Squ6 & 30 & 5 & 50.31 & 60.23 & 75.47 & 23 & 11 & 42.62 & 51.26 & 51.15 \\
\hline Squ7 & 29 & 14 & 50.66 & 60.58 & 58.45 & 32 & 11 & 40.41 & 49.04 & 48.49 \\
\hline Squ8 & 26 & 8 & 54.83 & 64.75 & 70.49 & 23 & 12 & 51.60 & 60.24 & 60.99 \\
\hline Squ9 & 37 & 10 & 30.22 & 40.14 & 36.94 & 36 & 10 & 52.89 & 61.53 & 64.65 \\
\hline Squ10 & 35 & 7 & 40.60 & 50.52 & 54.13 & 36 & 7 & 28.60 & 37.24 & 38.14 \\
\hline Squ11 & 10 & 1 & 0.00 & 9.92 & 0.00 & 11 & 6 & 59.19 & 67.82 & 82.86 \\
\hline Squ12 & 26 & 12 & 26.74 & 36.66 & 31.60 & 27 & 10 & 52.09 & 60.73 & 63.67 \\
\hline Squ13 & 26 & 10 & 48.03 & 57.95 & 58.71 & 25 & 10 & 42.63 & 51.27 & 52.10 \\
\hline Squ14 & 34 & 9 & 56.36 & 66.28 & 70.45 & 33 & 11 & 45.39 & 54.02 & 54.47 \\
\hline Squ15 & 35 & 14 & 37.23 & 47.15 & 42.96 & 36 & 11 & 55.44 & 64.07 & 66.52 \\
\hline Squ16 & 25 & 8 & 36.12 & 46.04 & 46.44 & 27 & 14 & 51.66 & 60.29 & 59.61 \\
\hline Squ17 & 20 & 10 & 40.32 & 50.24 & 49.28 & 22 & 7 & 44.55 & 53.18 & 59.39 \\
\hline Squ18 & 37 & 10 & 45.12 & 55.04 & 55.15 & 33 & 13 & 57.00 & 65.64 & 66.51 \\
\hline Squ19 & 30 & 9 & 40.52 & 50.44 & 50.65 & 26 & 14 & 58.45 & 67.08 & 67.44 \\
\hline Squ20 & 22 & 9 & 51.21 & 61.13 & 64.01 & 24 & 10 & 40.38 & 49.02 & 49.36 \\
\hline Squ21 & 29 & 12 & 44.90 & 54.82 & 53.06 & 3 & 2 & 1.11 & 9.75 & 3.33 \\
\hline Squ21' & N/A & N/A & N/A & N/A & N/A & 25 & 5 & 7.78 & 16.42 & 11.68 \\
\hline Squ22 & 26 & 12 & 45.87 & 55.79 & 54.21 & 26 & 11 & 54.03 & 62.67 & 64.84 \\
\hline Squ23 & 25 & 7 & 41.67 & 51.59 & 55.56 & 26 & 10 & 44.03 & 52.67 & 53.82 \\
\hline Squ24 & 4 & 4 & 15.67 & 25.59 & 26.12 & 29 & 11 & 17.79 & 26.42 & 21.34 \\
\hline Squ24' & 32 & 8 & 30.31 & 40.23 & 38.97 & 4 & 4 & 6.68 & 15.31 & 11.13 \\
\hline Average & 29 & 9 & 41.07 & 50.99 & 51.37 & 27 & 10 & 40.69 & 49.32 & 49.44 \\
\hline Total & 715 & 232 & $1,026.65$ & $1,274.64$ & $1,284.34$ & 702 & 271 & $1,057.83$ & $1,282.35$ & $1,285.45$ \\
\hline Genome coverage c (\%) & & & & 83.56 & 83.33 & & & & 83.88 & 83.81 \\
\hline
\end{tabular}




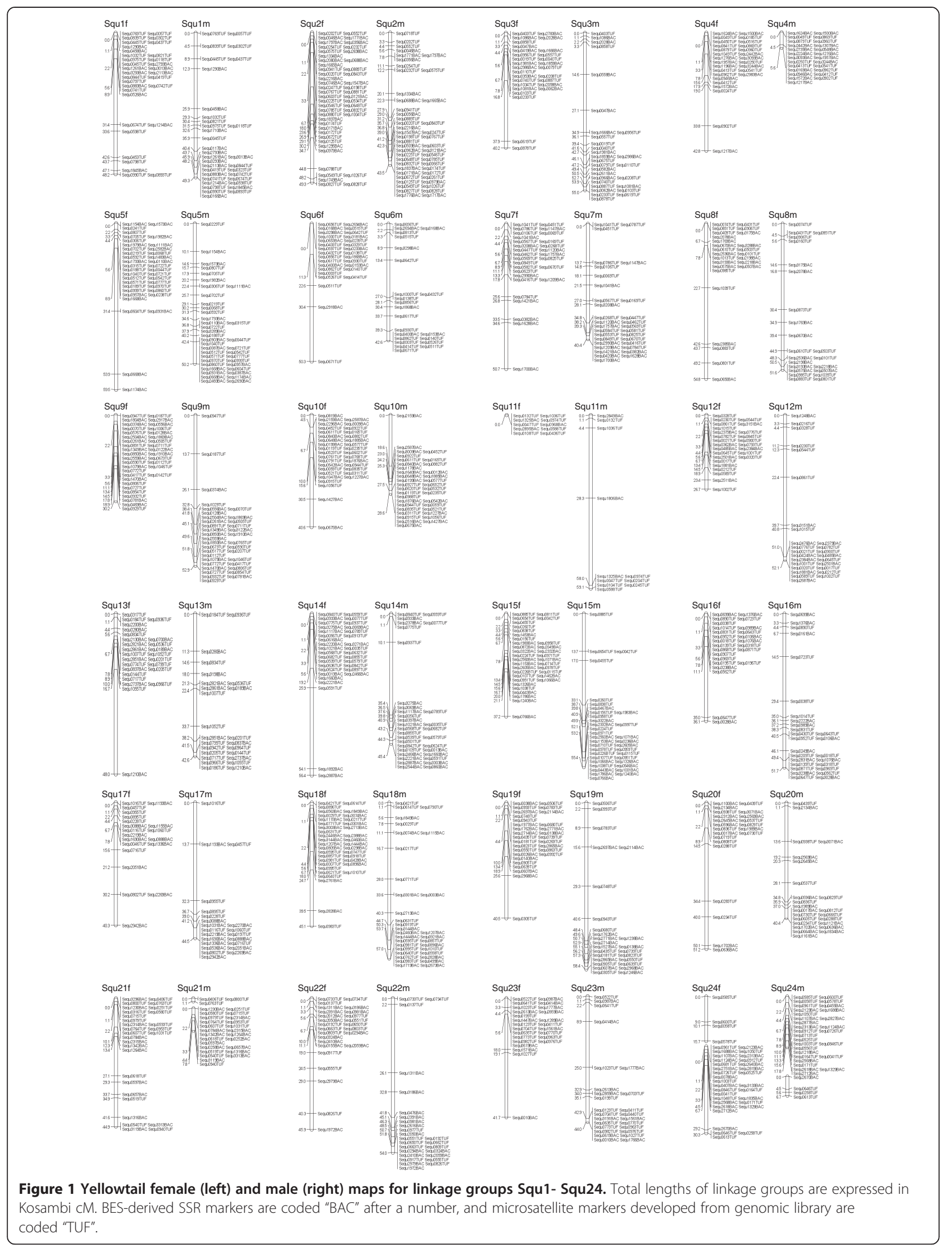


linkage groups had a one-to-two relationship, implying that chromosomal fusions or breakages occurred after divergence from ancestor of both species (Figure 2). Nevertheless, the result suggests conserved synteny between yellowtail and stickleback and hence the stickleback genome data would be useful as a reference of yellowtail genome.

\section{Conclusions}

We herein constructed a high-coverage BAC library and comprehensive genetic linkage map including BESderived SSR markers of yellowtail (Seriola quinqueradiata). A survey of BESs showed a low frequency of repetitive sequences as much as that of Tetraodon and fugu. BLAST searches and Oxford grids against five fish genomes clearly showed conservation between yellowtail and stickleback genome. Generally, a high repetitive sequence frequency hampers chromosome walking and makes the positional cloning difficult [32]. A low frequency of repetitive sequences and relatively small genome size suggest that yellowtail would be an ideal species to study the genetic basis of economically important traits. In addition, conserved genome architecture with stickleback would be helpful for synteny-based identification of new genetic markers and genes in the target genomic segments. We have already started studies regarding several traits such as sex determination and disease resistance $[20,33]$. We anticipate that the genomic and genetic resources we constructed will be powerful tools for further studies of these traits.

\section{Methods}

\section{Ethics statements}

Field permits are not required for this species in Japan. Since all fish treatments were performed in Goto Branch of Seikai National Fisheries Research Institute of Fisheries Research Agency, fish handling, husbandry and sampling methods were approved by Institutional Animal Care and Use Committee of National Research Institute of Aquaculture (IACUC-NRIA No. 03).

\section{BAC construction and BAC-end sequencing}

The BAC library was constructed according to Katagiri et al. with some modifications [14]. Briefly, at first, approximately $5 \times 10^{7}$ frozen sperm cells taken from one male yellowtail were embedded in agarose plugs, digested with proteinase $\mathrm{K}$ overnight at $37^{\circ} \mathrm{C}$ and stored in $0.5 \mathrm{M}$ EDTA following proteinase $\mathrm{K}$ inhibitor treatment until use. The plugs were dialyzed in $0.5 \times \mathrm{TE}$, partially digested with $\mathrm{MboI}$ and size fractionated by pulsefield electrophoresis. The fraction containing 150 to $250 \mathrm{~kb}$ genomic DNA was excised from the gel and was recovered as high molecular weight (HMW) genomic DNA. The HMW genomic DNA was then integrated into BamHI site of pBACe3.6 vector and reactions were transfected to E. coli DH10B strain. Finally, a total of 110,592 recombinant BAC clones were picked and stored in 288 384-well microtiter plates. The length of the insert DNAs was estimated by analyzing 100 BAC inserts digested with NotI.

The BESs were obtained from eight 384-well plates containing 3,072 clones. The BAC DNAs extracted by conventional alkaline lysis method were sequenced from SP6 and T7 sides with BigDye Terminator v3.1 Cycle Sequencing Kit (Life Technologies) following the manufacturer's instructions and reactions were electrophoresed with Applied Biosystems 3730 DNA Analyzer (Life Technologies). All raw reads were processed using PHRED software with default parameters except for the trimming error probability was set at $0.01[34,35]$, and vector and bacterial sequences were masked by CROSS_MATCH implemented in PHRAP software. The masked BESs of more than $100 \mathrm{bp}$ in length, hereafter called "qualified BES", were extracted using our in-house perl script. The GC content of the extracted BESs was estimated using the geecee program included in the EMBOSS package [36].

\section{Sequence data analysis}

Repetitive DNA elements in the qualified BESs, such as transposable elements and SSRs, were identified and masked using Crossmatch search engine (v1.090518), "teleostei" repeat database implemented in Repbase RepeatMasker Edition (20120418) and RepeatMasker program (see http://www.repeatmasker.org/ for details).

The repeat-masked qualified BESs were subjected to homology search. The eight fish proteome data sets (Atlantic cod: gadMor1.70, Tetraodon: TETRAODON8.70, medaka: MEDAKA1.70, Nile tilapia: Orenil1.0.70, platyfish: Xipmac4.4.2.70, stickleback: BROADS1.70, fugu: FUGU4.70 and zebrafish: Zv9.70) were obtained from Ensembl (ftp:// ftp.ensembl.org/). Only the longest protein for each gene was extracted and used for in-house database construction. For construction of genomic sequence database, the genomic sequences of stickleback (gasAcu1) and fugu (fr3) were downloaded from UCSC genome browser (http://hgdownload.soe.ucsc.edu/) and others from Ensembl.

BLAST searches were performed with qualified BESs as query with cut-off $e$-value $\mathrm{e}^{-9}$. The top hit querysubject pairs were extracted using in-house perl script under the criteria in which if multiple query-subject pairs were observed and were overlapped each other, only the most significant pair was considered significant.

\section{Development of SSR markers}

The SSR motifs and primer pairs in the qualified BESs were searched by WebSat online application (http:// wsmartins.net/websat/) with default settings except for 
product size, which was set to $100-200 \mathrm{bp}$. For each BAC clone, the SP6-side BES was at first analyzed and if no SSR motif or primer-binding site was found in the sequence, T7-side BES of the same clone was alternatively used. In both sides, the SSR motifs containing over six repeats were considered as real SSRs. In the case where more than two SSR motifs were found in one read, the longest one was used as a representative. Finally, 743 SSRs (89 mono-, 550 di-, 68 tri-, 31 tetra-, 4 penta- and 1 hexa-nucleotide repeats) were selected for primer design.

In addition to the BES-derived SSRs, we also developed microsatellite markers from the genomic library constructed by Ohara et al. [2,3]. The microsatellites containing CA/GT repeat motifs were isolated according to the protocol of Ohara et al. and primers were designed as described above $[2,3]$.

\section{Mapping panel}

The mapping panel consists of ninety progenies produced by artificial fertilization. Parent fish were caught off Goto Island, Nagasaki Prefecture, Japan and reared in a sea cage until they were matured with approximate body weight $7 \mathrm{~kg}$. Human chorionic gonadotropin (ASKA Pharmaceutical) was intramuscularly administered to the parent fish at $600 \mathrm{IU} / \mathrm{kg}$ body weight and eggs and sperm were taken at 45 hours after administration. Fertilized eggs were kept in $500 \mathrm{~L}$ seawater at approximately $19^{\circ} \mathrm{C}$ with $0.5-1 \mathrm{~L} / \mathrm{min}$ aeration until hatching. The juvenile fish were reared in $500 \mathrm{~L}$ seawater at $20-25^{\circ} \mathrm{C}$ until their body length reached $10 \mathrm{~cm}$. The caudal fin was partially clipped from each progeny as the DNA source and kept in absolute ethanol until use. Genomic DNA of each fish was extracted using DNeasy Blood and Tissue Kit (Qiagen) according to manufacturer's instructions.

\section{Data acquisition}

Genotyping was performed in an $11 \mu \mathrm{l}$ reaction volume containing $0.5 \mathrm{pmol} / \mu \mathrm{l}$ of unlabelled primer, $0.05 \mathrm{pmol} /$ $\mu \mathrm{l}$ of fluorescence-end-labeled primer with [5'-TET], $1 \times$ buffer, $2.0 \mathrm{mM} \mathrm{MgCl}_{2}, 0.2 \mathrm{mM}$ dNTP, $1.1 \mu \mathrm{g}$ of BSA, $0.025 \mathrm{U}$ of EX Taq DNA polymerase (Takara) and $25 \mathrm{ng}$ of template DNA. PCR was performed on a GeneAmp ${ }^{\circ}$ PCR System 9700 (Applied Biosystems), and the program conditions were $95^{\circ} \mathrm{C}$ for 2 min for initial denaturation, followed by 30 cycles of $30 \mathrm{sec}$ at $95^{\circ} \mathrm{C}, 1 \mathrm{~min}$ at the annealing temperature $\left(52-55^{\circ} \mathrm{C}\right), 1 \mathrm{~min}$ at $72^{\circ} \mathrm{C}$ and $10 \mathrm{~min}$ at $72^{\circ} \mathrm{C}$ for final extension. Amplification products were mixed with an equal volume of loading buffer (98\% formamide, $10 \mathrm{mM}$ EDTA, $0.05 \mathrm{w} / \mathrm{v} \%$ bromophenol blue), heated for $10 \mathrm{~min}$ at $95^{\circ} \mathrm{C}$ and then immediately cooled on ice. $2 \mu \mathrm{l}$ of each sample was loaded onto a 6\% PAGE-PLUS gel (Amresco) containing $8 \mathrm{M}$ urea and $0.5 \times$ TBE buffer. Electrophoresis was performed in
$0.5 \times$ TBE buffer, and after electrophoresis, the gel was scanned and imaged using a FLA-9000 image scanner (GE Healthcare).

\section{Linkage map construction}

Genotype data obtained above were subjected for linkage analysis for the male and the female meiosis independently. Marker genotypes were analyzed with LINKMFEX ver. 2.3 (http://www.uoguelph.ca/ rdanzman/software.htm). Linkage analysis was performed using genotype data converted to a backcross format. As the grandparent genotypes were unknown, pairwise analyses were performed, and markers were sorted in linkage groups at a minimum LOD score of 4.0. A goodness-of-fit for Mendelian segregation distortion was tested for all alleles using the chi-square test $(p<0.05$, d.f. $=1)$. Finally, the marker order was determined and double recombination events were checked with MapManagerQTX version 2.0 [37]. The resultant genetic map was visualized using MapChart version 2.2 [38].

The genome length $L$ was estimated using two different methods following Fishman et al. [39]. In the first method $\left(L_{1}\right)$, average marker interval was estimated by dividing the summed length of all linkage groups by the number of intervals, and twice the average marker interval was added to each linkage group. In the second method $\left(L_{2}\right)$, the length of the each linkage group was multiplied by the factor $(m+1) /(m-1)$, where $m$ is the number of framework markers on the linkage groups. Finally, genome coverage $c$ of the linkage map was estimated by calculating $c=1-e^{-2 d n / L}$, where $d$ is the average interval of markers, $n$ is the number of markers, and $L$ is the genome length estimated above.

\section{Identification orthologous chromosomes with other fishes} The flanking sequences obtained from all SSR markers assigned to the yellowtail linkage groups were used for the BLASTn search against genomic sequences of medaka, Tetraodon, stickleback, fugu and zebrafish with a cut-off $e$-value of 0.01 . The top hit query-subject was extracted using in-house perl script. In the case where multiple hits were obtained, we defined orthology as follows; let us consider only the first, second and third top hit, if query position of the first and second/third top hit is overlapped each other and quotient of $e$-value of the first hit divided by that of the second/third hit is greater than $10^{-3}$, the hit is considered to be an unclear orthologous pair and rejected. The substantial hits were processed for constructing Oxford grid using Grid Map ver. 3.0a (http://cbr.jic.ac.uk/dicks/software/Grid_Map/).

\section{Availability of supporting data}

All the supporting data are included as additional files. 


\section{Additional file}

Additional file 1: SSR markers in the yellowtail map. Marker name, linkage group, polymorphic information (1: polymorphic in both female and male, 2: polymorphic in only female, 3: polymorphic in only male), genotype of dam and sire, kind of repeat motif number, repeat type, primer sequences, annealing temperature, PCR product size, and GenBank accession number are shown.

\section{Competing interests}

The authors declare they have no competing interests.

\section{Authors' contributions}

KF performed all molecular experiments, constructed the linkage map and drafted the manuscript. TK analyzed all data and drafted the manuscript. WK contributed to data analysis. SK helped SSR marker genotyping. KY performed fish breeding. AO took part in developing the linkage analysis pipeline. JA, YK, KA, and TT provided laboratory facilities and support this program in all steps. NO and TS conceived and overlooked the project and reviewed the manuscript. All authors read and approved the final manuscript.

\section{Acknowledgements}

We thank Misato Fujii for providing technical help in SSR genotyping, Kazuharu Nomura in NRIFS for his support with the analysis of measure an estimated genome size of yellowtail. This research was supported by the Program for Promotion of Basic and Applied Researches for Innovations in Bio-oriented Industry (BRAIN) and by grants-in-aid for Scientific Research "New Technology of Fish Breeding" from Fisheries Research Agency of Japan.

\section{Author details}

${ }^{1}$ Faculty of Marine Science, Tokyo University of Marine Science and Technology, 4-5-7, Konan, Minato-ku, Tokyo 108-8477, Japan. ${ }^{2}$ Fisheries Research Agency, National Research Institute of Aquaculture, 422-1, Nakatsuhamaura, Minami-ise-cho, Watarai-gun, Mie 516-0193, Japan. ${ }^{3}$ Fisheries Research Agency, Goto Branch of Seikai National Fisheries Research Institute, 122-7, Nunoura, Tamanoura-cho, Fukue-shi, Nagasaki 853-0508, Japan.

Received: 13 September 2013 Accepted: 26 February 2014 Published: 31 March 2014

\section{References}

1. Kocher TD, Kole C: Genome Mapping and Genomics in Fishes and Aquatic Animals. Berlin: Springer; 2008.

2. Ohara E, Nishimura T, Nagakura Y, Sakamoto T, Mushiake K, Okamoto N: Genetic linkage maps of two yellowtails (Seriola quinqueradiata and Seriola lalandi). Aquaculture 2005, 244:41-48.

3. Ohara E, Nishimura T, Sakamoto T, Nagakura Y, Mushiake K, Okamoto N: Isolation and characterization of microsatellite loci from yellowtail Seriola quinqueradiata and cross-species amplification within the genus Seriola. Mol Eco Notes 2003, 3:390-391.

4. Chen M, Presting G, Barbazuk WB, Goicoechea JL, Blackmon B, Fang G, Kim $H$, Frisch D, Yu Y, Sun S, Higingbottom S, Phimphilai J, Phimphilai D, Thurmond S, Gaudette B, Li P, Liu J, Hatfield J, Main D, Farrar K, Henderson C, Barnett L, Costa R, Williams B, Walser S, Atkins M, Hall C, Budiman MA, Tomkins JP, Luo M, et al: An integrated physical and genetic map of the rice genome. Plant Cell 2002, 14:537-545.

5. Budiman MA, Mao L, Wood TC, Wing RA: A deep-coverage tomato BAC library and prospects toward development of an STC framework for genome sequencing. Genome Res 2000, 10:129-136.

6. International Human Genome Sequencing Consortium: Initial sequencing and analysis of the human genome. Nature 2001, 409:860-921.

7. Shizuya H, Birren B, Kim UJ, Mancino V, Slepak T, Tachiiri Y, Simon M: Cloning and stable maintenance of 300-kilobase-pair fragments of human DNA in Escherichia coli using an F-factor-based vector. Proc Natl Acad Sci U S A 1992, 89:8794-8797.

8. Myosho T, Otake H, Masuyama H, Matsuda M, Kuroki Y, Fujiyama A, Naruse K, Hamaguchi S, Sakaizumi M: Tracing the emergence of a novel sex-determining gene in medaka, Oryzias luzonensis. Genetics 2012, 191:163-170.
9. Buitkamp J, Kollers S, Durstewitz G, Fries R, Welzel K, Schäfer K, Kellermann $\mathrm{A}$, Lehrach $\mathrm{H}$ : Construction and characterization of a gridded cattle BAC library. Anim Genet 2000, 31:347-351.

10. Fahrenkrug SC, Rohrer GA, Freking BA, Smith TP, Osoegawa K, Shu CL, Catanese JJ, de Jong PJ: A porcine BAC library with tenfold genome coverage: a resource for physical and genetic map integration. Mamm Genome 2001, 12:472-474.

11. Vaiman D, Billault A, Tabel-Aoul K, Schibler L, Vilette D, Oustry-Vaiman A Soravito C: Construction and characterization of a sheep BAC library of three genome equivalents. Mamm Genome 1999, 10:585-587.

12. Thorsen J, Zhu BL, Frengen E, Osoegawa K, de Jong PJ, Koop BF, Davidson WS, Hoyheim B: A highly redundant BAC library of Atlantic salmon (Salmo salar): an important tool for salmon projects. BMC Genomics 2005, 6:50.

13. Liu H, Jiang Y, Wang S, Ninwichian P, Somridhivej B, Xu P, Abernathy J, Kucuktas H, Liu Z: Comparative analysis of catfish BAC end sequences with the zebrafish genome. BMC Genomics 2009, 10:592.

14. Katagiri T, Asakawa S, Minagawa S, Shimizu N, Hirono I, Aoki T: Construction and characterization of BAC libraries for three fish species; rainbow trout, carp and tilapia. Anim Genet 2001, 32:200-204.

15. Xu P, Li J, Li Y, Cui R, Wang J, Wang J, Zhang Y, Zhao Z, Sun X: Genomic insight into the common carp (Cyprinus carpio) genome by sequencing analysis of BAC-end sequences. BMC Genomics 2011, 12:188.

16. Whitaker HA, MCAndrew BJ, Taggart JB: Construction and characterization of a BAC library for the European sea bass Dicentrarchus labrax. Anim Genet 2006, 37:526.

17. Kuhl H, Beck A, Wozniak G, Canario AV, Volckaert FA, Reinhardt R: The European sea bass Dicentrarchus labrax genome puzzle: comparative BAC-mapping and low coverage shotgun sequencing. BMC Genomics 2010, 11:68.

18. Wang CM, Lo LC, Feng F, Gong P, Li J, Zhu ZY, Lin G, Yue GH: Construction of a BAC library and mapping BAC clones to the linkage map of Barramundi, Lates calcarifer. BMC Genomics 2008, 9:139.

19. Ammiraju JS, Luo M, Goicoechea JL, Wang W, Kudrna D, Mueller C, Talag J, Kim H, Sisneros NB, Blackmon B, Fang E, Tomkins JB, Brar D, MacKill D, McCouch S, Kurata N, Lambert G, Galbraith DW, Arumuganathan K, Rao K, Walling JG, Gill N, Yu Y, SanMiguel P, Soderlund C, Jackson S, Wing RA: The Oryza bacterial artificial chromosome library resource: construction and analysis of 12 deep-coverage large-insert BAC libraries that represent the 10 genome types of the genus Oryza. Genome Res 2006, 16:140-147.

20. Fuji K, Yoshida K, Hattori K, Ozaki A, Araki K, Okauchi M, Kubota S, Okamoto N, Sakamoto T: Identification of the sex-linked locus in yellowtail, Seriola quinqueradiata. Aquaculture 2010, 308:S51-S55.

21. Genet C, Dehais P, Palti Y, Gao G, Gavory F, Wincker P, Quillet E, Boussaha M: Analysis of BAC-end sequences in rainbow trout: content characterization and assessment of synteny between trout and other fish genomes. BMC Genomics 2011, 12:314.

22. Xu P, Wang S, Liu L, Peatman E, Somridhivej B, Thimmapuram J, Gong G, Liu Z: Channel catfish BAC-end sequences for marker development and assessment of syntenic conservation with other fish species. Anim Genet 2006, 37:321-326.

23. Shirak A, Grabherr M, Di Palma F, Lindblad-Toh K, Hulata G, Ron M, Kocher $T D$, Seroussi E: Identification of repetitive elements in the genome of Oreochromis niloticus: tilapia repeat masker. Mar Biotechnol (NY) 2010, 12:121-125.

24. Roest Crollius H, Jaillon O, Dasilva C, Ozouf-Costaz C, Fizames C, Fischer C, Bouneau L, Billault A, Quetier F, Saurin W, Bernot A, Weissenbach J: Characterization and repeat analysis of the compact genome of the freshwater pufferfish Tetraodon nigroviridis. Genome Res 2000, 10:939-949.

25. Nelson JS: Fishes of the World. 4th edition. New Jersey: Wiley; 2006

26. Sarropoulou E, Nousdili D, Magoulas A, Kotoulas G: Linking the genomes of nonmodel teleosts through comparative genomics. Mar Biotechnol (NY) 2008, 10:227-233.

27. Liu S, Rexroad CE 3rd, Couch CR, Cordes JF, Reece KS, Sullivan CV: A microsatellite linkage map of striped bass (Morone saxatilis) reveals conserved synteny with the three-spined stickleback (Gasterosteus aculeatus). Mar Biotechnol (NY) 2012, 14:237-244.

28. Ojima Y, Yamamoto K: Cellular DNA contents of fishes determined by flow cytometry. La Kromosomo // 1990, 57:1871-1888.

29. Massault C, Bovenhuis H, Haley C, de Koning DJ: QTL mapping designs for aquaculture. Aquaculture 2008, 285:23-29. 
30. Streelman JT, Albertson RC, Kocher TD: Genome mapping of the orange blotch colour pattern in cichlid fishes. Mol Ecol 2003, 12:2465-2471.

31. Roberts RB, Ser JR, Kocher TD: Sexual conflict resolved by invasion of a novel sex determiner in Lake Malawi cichlid fishes. Science 2009, 326:998-1001

32. Locke J, Podemski L, Aippersbach N, Kemp H, Hodgetts R: A physical map of the polytenized region (101EF-102F) of chromosome 4 in Drosophila melanogaster. Genetics 2000, 155:1175-1183.

33. Ozaki A, Yoshida K, Fuji K, Kubota S, Kai W, Aoki J, Kawabata Y, Suzuki J, Akita K, Koyama T, Nakagawa M, Hotta T, Tsuzaki T, Okamoto N, Araki K, Sakamoto T: Quantitative trait loci (QTL) associated with resistance to a parasitic disease (Benedenia seriolae) in yellowtail (Seriola quinqueradiata) through genome wide analysis. PLOS ONE 2013, 8:e64987.

34. Ewing B, Hillier L, Wendl MC, Green P: Base-calling of automated sequencer traces using phred. I. Accuracy assessment. Genome Res 1998, 8:175-185.

35. Ewing B, Green P: Base-calling of automated sequencer traces using phred. II. Error probabilities. Genome Res 1998, 8:186-194.

36. Rice P, Longden I, Bleasby A: EMBOSS: the European molecular biology open software Suite. Trends Genet 2000, 16:276-277.

37. Manly KF, Olson JM: Overview of QTL mapping software and introduction to Map manager QT. Mamm Genome 1999, 10:327-334.

38. Voorips RE: Mapchart software for the graphical presentation of linkage maps and QTLs. J Hered 2002, 93:77-78,

39. Fishman L, Kelly AJ, Morgan E, Willis JH: A genetic map in the Mimulus guttatus species complex reveals transmission ratio distortion due to heterospecific interactions. Genetics 2001, 159:1701-1716.

doi:10.1186/1756-0500-7-200

Cite this article as: Fuji et al:: Construction of a high-coverage bacterial artificial chromosome library and comprehensive genetic linkage map of yellowtail Seriola quinqueradiata. BMC Research Notes 2014 7:200.

\section{Submit your next manuscript to BioMed Central and take full advantage of:}

- Convenient online submission

- Thorough peer review

- No space constraints or color figure charges

- Immediate publication on acceptance

- Inclusion in PubMed, CAS, Scopus and Google Scholar

- Research which is freely available for redistribution 